\title{
The Current Status of Hospital Information Systems in Yanbian, China
}

\author{
Jeongeun Kim ${ }^{1,2}$, Meihua Piao ${ }^{3}$, Jingwu, $\mathrm{Wu}^{3}$ \\ College of Nursing Seoul National Univ., Seoul, Korea ${ }^{1}$, \\ Research Institute of Nursing Science, Seoul National Univ., Seoul Korea ${ }^{2}$, \\ Master's course, College of Nursing Seoul National Univ., Seoul, Korea ${ }^{3}$
}

\begin{abstract}
Purpose: The purpose of this study was to analyze the current status of Hospital Information system in Yanbian, China. Methods: Structured self-administered questionnaires were sent to hospitals in Yanbian to survey the issues and six hospitals answered. Data were analyzed by using Windows SPSS 12.0. Results: All facilities were second-grade national hospitals with 100 500 beds, kept about 40 computers and all used internet. Four of them had information exclusive department, and the other two had the implementation plans. All of the hospitals had Patient Billing System and some features of Medication Administration System. Four hospitals had administration systems, and the other two had no plans to develop or adopt administration system in the next three years. Two hospitals used the packages composed of Electronic Data Interchange System, Amount Receivable Management System and Laboratory Information System. One hospital used the Picture Archiving and Communication System, Telemedicine System, Radioactive Examination. Conclusions: Compared with Korea, the results showed relevant explanation on the delays of implementing HIS and its current status in Yanbian. In order to develop Hospital Information System, various strategies must be developed and active international support and research was required to provide the appropriate experiences.

(Journal of Korean
\end{abstract}

Society of Medical Informatics 15-1, 133-140, 2009)

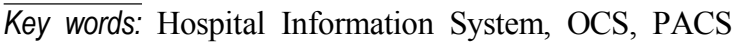

Received for review: July 3, 2008; Accepted for publication: February 9, 2009.

Comesponding Author: Meihua Piao, Seoul National University, College of Nursing Old Department \#308 28 YEONGEON-DONG, JONGRO-GU, SEOUL, REPUBLIC OF KOREA, 110-744

Tel: +82-2-740-8473, Fax: +82-2-761-4103, E-mail: parkmihua@snu.ac.kr 


\section{Introduction}

Hospital information systems (HIS) have been developed and used since the mid-1960 ${ }^{1}$. Originating from medical technology research and development, they played an important role in reducing clinical errors, supporting health care professionals, increasing the efficiency of care, or even improving the quality of patient care. Hospital information system was a comprehensive, integrated information system designed to manage the administrative, financial and clinical aspects of the hospital ${ }^{2}$.

In China, computers were first used in the hospitals since 1970s, but it was only until 1984 when HIS was applied ${ }^{3)}$ and the Golden Health project launched by Ministry of Health of P. R. China in 1995 marked the beginning of HIS development and adoption by hospitals all around china. According to an investigation progressed by Chinese Ministry of Health in 2004, about 6,063 hospitals among 15,924 established $\mathrm{HIS}^{4)}$. It was estimated that about $70 \%$ of county hospitals and above had constructed HIS by now. Moreover, the cost of HIS development and management was also increasing. Comparing with what was in 2003, the total cost for health information technology in China was increased by $25 \%$ in 2004, which was 84.7 million US dollars $^{5)}$. However, in contrast with its rapid development, the current situation of HIS in China showed no optimism. One important characteristic was that the development of HIS differs a lot among regions. By 2004, the proportion of hospitals with HIS in east China was above $80 \%$, while in northwest, it was less than $20 \%$. Another problem can be listed as the lack of unified software system. Because many HIS were developed free, so the software had no standards or the unified platform. Moreover HIS related companies were in different levels, and didn't familiar with the style of hospital management or workflows, and some companies only considered the current benefits without long term investment. Furthermore, some companies even thought that HIS market had potential, so they made some simple system packages together, and took some measures to deceive the users ${ }^{6}$.

In order to solve the problem, great efforts had been done by the government in recent years. One of the projects directed by the government was "National Health Information Development Plan, 2003-2010". In this plan all the hospitals at level 3 and level 2 would have MIS, and $60 \%$ of country level hospitals would have MIS by 2008. Ten model digital hospitals with clinical IS such as EPR, PACS/RIS, LIS, Doctor/nurse workstations would be constructed by 2010 . Network between health administration and preventive healthcare system would be done by $2008^{7)}$.

China International Broadcasting's "2006-2020 Tactics for national digitalization planning of hospitals" announced that, from studying the current and future hospital digitalization of China, in the next 5 years, China would drive forward the construction of national digitalization planning of hospitals and rise the benefit and quality of economical growth ${ }^{9}$. According to the Department of Commerce, China's hospital digitalization annual investment was 332.71 billion Yuan and among which 52.0 billion Yuan, 50.48 billion Yuan, 44.8 billion Yuan was specifically for the investment in the 3 major aspects of Electronic communication, government, and finance respectively ${ }^{10)}$. In 2003, rural city level hospital was still in the network construction stage and larger scale hospitals were facing the problems of system transition and network upgrade/expansion. According to the related data, 2003 and 2004 most medical businesses were in the process of basic network construction, and about $20 \sim 30 \%$ growth rate was predicted. Due to SARS, hospital digitalization became a priority among the business areas, and larger need for application software has emerged.

Yanbian was placed in Jilin province, in the northeastern part of China. It was designated as an autonomous prefecture due to the large number of ethnic Koreans living in the region. The prefectural capital was Yanji, and the area was 42,700 $\mathrm{km}^{2}$ with the population of 2,184,000. Yanbian had set up an efficient network of health care centers and hospitals, including the Yanbian Hospital, tuberculosis treatment center, anti-epidemic hospital, psychiatric sanatorium and so on. The total number of health care facilities was 232 , of which there were 22 main hospitals composed of one tertiary hospital, 8 traditional Chinese medical hospitals, and 13 secondary hospitals. There were also 10,484 healthcare providers, of which 3,970 medical doctors, 3,657 resident nurses ${ }^{11)}$. The total bed number was 8,283 which 
means 37 beds per 10,000 people. Yanbian boasted high standards of maternity, childcare and family planning, as well as an enviable record in the fight against endemic diseases. With the improvement of living standard the government made great effort to improve healthcare services and invested millions of RMB to construct health care facilities and other related infrastructure. Compared with developed region, however the status of medical facilities was still in the low level, specially the construction of Hospital Information System. After SARS, regional information system and patient information sharing were emphasized and moreover, the Chinese central government wanted to reduce the disparity of differences among regions not only in economics but also in the healthcare services, and constructing Hospital Information System became the major point in recent years. However few systematic researches were done about the status of hospital information system, especially in particular regions like Yanbian. Therefore, it was meaningful to investigate the current status of hospital information system in Yanbian, to explore the countermeasures for constructing standardized and internationalized systems which simulate different grade hospitals and many related organizations into a big integer.

The goal of this study was to investigate the hospital information system in Yanbian region of China and to understand the digitalization of healthcare centers. Following is the list of detailed objectives.

1) Investigate the current development of hospital information system of Yanbian region by applying the survey tools for the hospital digitalization developed in Korea.

2) Analyze the perception of hospital digitalization of medical professors, especially hospital managers.

3) Compare and analyze the level of hospital digitalization with that of Korea's and the need for development in future Chinese healthcare information system.

\section{Materials and Method}

Structured self-administered questionnaires were sent to the hospitals in Yanbian to survey the issues, and collected from August $1^{\text {st }} 2007$ to August $30^{\text {th }} 2007$. The questionnaire was designed by the Health Insurance Review \& Assessment Service for the purpose of diagnosing the hospital information systems' situation in Korea ${ }^{8)}$. The original questionnaire was modified to fit the Yanbian hospitals current situation.

In order to understand the construction of HIS level systematically, we sent the questionnaires to the hospital managers who were all resident medical doctors and were familiar with the present circumstances. Data were analyzed by using Windows SPSS 12.0 version.

\section{Results}

\section{General Characteristics}

A total of 6 hospital managers, and medical staffs (ratio of retrieval, 27\%) answered the questionnaire and they were all second-grade national hospitals with 100 500 beds.

In China, hospitals can generally be categorized into three levels of primary, secondary and tertiary, depending on the nature of services provided. Primary hospitals provide community health services to local communities with the population of less than one hundred thousand. The number of beds ranges from 20 to 100 . Secondary hospitals encompass services that are most commonly provided in the in-patient setting and are curative in nature. They provide services to regions with population of more than one hundred thousand and the number of beds ranges from 100 to 500 . Tertiary hospitals are the highest level of healthcare system and encompass the more complex, special, and costly in-patient treatment services and the number of beds are more than $500^{12)}$. 


\section{Status of Hospital Information System}

\section{(1) Infrastructures}

As shown in Table 1, all of the 6 hospitals had more than 40 computers and used ADSL (Asymmetric digital subscriber line), Leased Line or LAN. Five of the hospitals backed up their systems daily, and other did so only once or twice per week. Of the six hospitals, four had separate backup devices such as CD-RW, DVD-RW, Portable Hard Drivers or Web-Disk and they were all connected by the network. Four hospitals had information exclusive department, and the other two did not, but they had plans to implement.

\section{(2) Usage of subsystems}

All of the hospitals had Patient Billing System and some features of Medication Administration System. In such case, three hospitals had self-developed, two bought the packages, and one obtained it from a commercial vendor. Four hospitals had administrative systems, in which three of them self developed, one bought the package, and the other two that didn't have administrative system had plans to develop one in the next three years. Two hospitals used the package composed of Insurance Management System, Amount Receivable Management System and Laboratory Information System. One hospital used the package of PACS, Telemedicine System, Radioactive Examination System, and the other hospitals had no plans of using such types of systems. All hospitals had no CPOE System, but they have plans to develop in the next three years (Table 2).

\section{(3) Overall evaluation towards HIS implementation}

Five hospitals agreed that they have insufficient hospital information service, fund and also lack substantial amount of staff for critical factors required for successful acquisition and implementation. Four hospitals answered "neutral" on the issue of insufficiency in education, user perception, law and policy. On the question regarding whether information system would return benefits on investments, three hospitals agreed and two answered "neutral". Four hospitals answered that implementation of hospital information service can yield positive outcome.

Table 1. Infrastructure status

\begin{tabular}{lcccccc}
\hline & Hospital A & Hospital B & Hospital C & Hospital D & Hospital E & Hospital F \\
\hline Below 486 & & & & & 1 & \\
Pentium PC & & & & & 7 & 1 \\
Pentium II PC (including Celeron PC) & 10 & 30 & & 10 & 23 & \\
Pentium III PC & 5 & 12 & 10 & 25 & 17 & 125 \\
Pentium IV PC & 75 & & 50 & 42 & 50 & 125 \\
\hline$\quad$ Total & 80 & 42 & 60 & & &
\end{tabular}

Table 2. Utilization status of HIS subsystems by implementation types

\begin{tabular}{|c|c|c|c|c|c|c|}
\hline \multirow{2}{*}{ Programs } & \multicolumn{3}{|c|}{ Using } & \multicolumn{2}{|c|}{ Not using } & \multirow{2}{*}{ Total } \\
\hline & In-house develop & Vendor develop & Package purchasing & Within 3 years & No plans & \\
\hline Inpatient/Outpatient OCS & & & & $6(100)$ & & $6(100.0)$ \\
\hline Pharmacy, Patient Billing & $3(50.0)$ & $1(16.7)$ & $2(33.3)$ & & & $6(100.0)$ \\
\hline Administration & $3(50.0)$ & & $1(16.7)$ & $2(33.3)$ & & $6(100.0)$ \\
\hline Insurance Management & & $2(33.3)$ & & $4(66.7)$ & & $6(100.0)$ \\
\hline Amount Receivable Management & & 2(33.3) & & $4(66.7)$ & & $6(100.0)$ \\
\hline Laboratory Information & & $2(33.3)$ & & & $4(66.7)$ & $6(100.0)$ \\
\hline PACS, Telemedicine, Radiology & $1(16.7)$ & & & & $5(83.3)$ & $6(100.0)$ \\
\hline $\begin{array}{l}\text { Special Treatment, Referral, } \\
\text { Inpatient/Outpatient EMR, ERP, DW, } \\
\text { KMS, CRM, Health check-up }\end{array}$ & & & & & $6(100)$ & $6(100.0)$ \\
\hline
\end{tabular}


(4) Information utilization using HIS

\section{1) Computer Usage Time}

The average computer usage time by the staff was 6 to 10 hours per day in five hospitals, and one hospital responded less than 5 hours. All of the hospitals responded that doctors used computer less than 5 hours per day. Therefore, we can estimate that computers were used more in administrative work than in clinical practice (Table 3).

\section{2) Homepage Construction}

Of the 6 hospitals, four had established homepages or in development stage. Three of them were developed by commercial vendors and the other one was developed by the hospital staff. Only one hospital updated the homepage whenever needed. Services provided from the homepage were introduction or guidance of the hospital, bulletin board, health information and so on. None of the hospital did the analysis of homepage application, and in all cases hospital staffs are in charge of homepage management.
3) Perception of providing Internet Health Information

About providing health information via the internet, five hospitals responded "strongly agreed" or "agreed", and only one hospital responded "neutral" (Table 4). As was shown, most of the hospitals had positive recognition about the delivery of health information. Therefore, we can estimate that with the increase of the computer and internet in use, the need of informatics in health care domain was increased.

4) Method of acquiring medical knowledge

For the question on how doctors acquire medical knowledge and relevant information, most of them preferred to use homepages and the Journal of Medical Association. The next preferred were Newsletter of Medical Association, online journals, related journals from the specialized societies and etc (Table 5).

Table 3. Computer usage time

\begin{tabular}{|c|c|c|c|c|}
\hline & \multicolumn{4}{|c|}{ Respondence (\%) } \\
\hline & Less than 5 hours & $6 \sim 10$ hours & More than 11 hours & Total \\
\hline Physicians & $1(16.7)$ & $5(83.3)$ & 0 & $6(100.0)$ \\
\hline Other staffs & $6(100.0)$ & 0 & 0 & $6(100.0)$ \\
\hline
\end{tabular}

Table 4. Perception of providing Internet Health Information

\begin{tabular}{|c|c|c|}
\hline Item & Respondence & $(\%)$ \\
\hline Strongly Agree & 1 & 16.7 \\
\hline Agree & 4 & 66.7 \\
\hline Undecided & 1 & 16.7 \\
\hline Disagree & 0 & 0 \\
\hline Strongly Disagree & 0 & 0 \\
\hline
\end{tabular}

Table 5. The method of acquiring medical knowledge

\begin{tabular}{|c|c|c|c|c|c|}
\hline Item & response & $(\%)$ & Item & response & $(\%)$ \\
\hline Related homepage & 6 & 100.0 & Related journals from the specialized societies & 3 & 50.0 \\
\hline E-learning & 1 & 16.7 & Newsletter of Medical Association & 4 & 66.7 \\
\hline Online journal & 3 & 50.0 & Journal of Medical Association & 5 & 83.3 \\
\hline E-mail & 2 & 33.3 & Others & & \\
\hline Related CD & 2 & 33.3 & & & \\
\hline \multicolumn{3}{|c|}{ Total } & 6 & & \\
\hline
\end{tabular}




\section{Discussion}

Comparing with Korea, the results showed relevant explanation for the delays of implementing HIS and its current status in Yanbian, China. Active international support and researches are required to provide the experience and strategies for developing Hospital Information System. It is assessed that Yanbian current hospital digitalization level is similar to Korea's early hospital digitalization efforts, therefore it will be beneficial for both countries to help China implement the suitable methods that were used in Korea through sufficient alteration and economical systematic approach.

In this research only six second grade hospitals participated although there were 21 second grade hospitals in Yanbian. The reasons were some hospitals didn't use hospital information system or some answers were not reliable. However, the six hospitals were all funded by Chinese government, and considered to be the main hospitals which can represent the second grade hospitals in Yanbian. Therefore, use the information to analyze current status of hospital information system is feasible.

In June $23^{\text {rd }} 2003$, Weekly China Science Technology Trend magazine, citing the China Communication Webpage, announced the following. In 2002, even though China's ADSL development was relatively weak, in terms of the broad band connection aspect, swiftly gained a leading position. In 2003, China's ADSL is predicted to become the most popular industry in the market. As of June 2003, ADSL broad band member of China is at 4 million and by the end of 2003, the number will increase to 7 million. Overall ratio of people with Broadband connection in China is still relatively low. China's 'Chulkang province', where the broadband connection is developing the fastest, has only $3 \%$ supply rate compared to $20 \%$ of other advanced countries. Also among the 45.8 million internet connection members, the number of ADSL connection members is small. Current state of China's internet development is still at its beginning, however the predicted development and potential is promising. Out of the 20 digitalization guideline announced by the Chinese government, 16 of them are related to electronic commerce, of which include electronic government, electronic commerce, distance learning, and telemedicine that use telecommunication network technology are becoming the important means of hospitals digitalization in several aspects. Also the investment in hospitals digitalization field is predicted to expand continuously. In 2003, 23 billion Yuan was planned to be invested toward IT, specifically hardware, software and information service investment ratio will be $66.5 \%, 25.7 \%$ and $7.8 \%$ respectively. Among them, for the medical institutions that was not constructed in the first half year, $27.8 \%$ of LAN will be developed presently, also $45.5 \%$ of websites that were not constructed is planned to be materialized.

Development of Information Technology and Chinese medical industry brought accelerated growth in 2002 Chinese hospital digitalization process. Also, network construction project was launched, and hospital digitalization foundation institution construction received benefits. Aside from this, "3 networks and 1 Base" construction has been actively promoted, electronic government is making a continuous progress and hospital digitalization achieved concrete goals. From the 2002 IT investment, medical business developed very quickly with 38.3\% growth rate and 1.84 billion Yuan. Hardware, software and information service investment ratio were $69.6 \%, 23.3 \&$ and $7.1 \%$ respectively. In medical information system construction, server and network equipment are the core components, where total market scale and user numbers are increasing significantly. In 2002, medical network product consumption was 340 million Yuan, including desktop computers and printers as means of information terminal user equipments where a large scale market was formed. Compared to the 48,500 desktop computer consumption, laptop computers as portable terminal are not as popular in the hospitals and the market for them is relatively small. On June $1^{\text {st }} 2003$, China High Technology Industry News reported that medical business consumption toward software products make up $23.3 \%$ of the entire consumption, where the medical applications software market shows promising future and rapidly emerged as competitive ${ }^{13)}$. 
Recently, a CEO of large scale hospital in Beijing visited in order to understand Korea's current digitalization statue of the hospitals, reflecting the increased interest of Chinese physicians. He explained about the various efforts being made to support the development of legislative, regime and technology for medical information system implementation ${ }^{14)}$. Under the opinion of hospital digitalization being lead by physicians, Chinese physicians are making long term goals in national scale, presented their overall opinions to the government and currently debating the issue. However, the current level of China's digitalization of hospitals is at its infancy and there are large gaps among different regions, therefore it is predicted that in order to achieve successful national hospital digitalization goals, large amount of time and effort is required. In relation to that, efforts such as announcing Medical Information Generalization Guidelines, including HL7, in May 2002, networking with International conferences and hosting conferences are being made and epochal development centering around PACS and OCS is predicted. It has been observed that with the Beijing Olympics looming closer, Chinese government and the medical society is showing strong determination towards hospital digitalization. Currently, Chinese government is providing maximum support to hospitals that are implementing hospital information systems including OCS, PAC and LIS and specifically, the Communist Party in Cho-Yang district of Beijing announced that "All hospitals located in Beijing must be digitalized as soon as possible". The need for hospital digitalization is not only urged on by the Chinese government but also by the physicians and currently majority of the physicians view the digitalization of hospitals as one of the trends where they predict that hospital digitalization as a necessity, especially after joining WTO in 2001. Within China, there are over 12 thousand hospitals that have the capacity of at least 200 patients and 20 to $30 \%$ out of those that have patient capacity of over 400 uses computers. Hospitals located along the coastal region have achieved more digitalization, whereas those located in inlands have not achieved ${ }^{15)}$.

As Yanbian is a region with relatively slow development and also home to many Korean descents living in China, continuous concern and effort as well as developing appropriate exporting strategy and using thorough assessment of the market are required. Also, in order to systematically implement development aspects of Hospital Information System according to each Yanbian hospital's characteristic, mutual efforts from the government, academia and industries are required.

However, there were some limitations in this research. the only one tertiary hospital didn't participate in the survey because of not allowing expose their information. This tertiary hospital actively used the hospital information system, and can mostly represent the current level. Not including the hospital may lead some limitations for exactly exploring the status of hospital information system.

\section{REFERENCE}

1. W. E. Hammond, Hospital information system: a review in perspective. Yearbook Medical Information, 1994; p.95-102.

2. Kim CY, Lee JS, Kim BY, Kim YI, and Shin Y, Introduction and the Current Status of Hospital Information Systems. J Korean Soc Med Informatics, 1999; 5(1): p.27-35.

3. Jin XZ, C.M., Hospital Information System. Beijing: Science Press; 2004.

4. Zhang Y, Xu Y, Shang L, Rao K. An investigation into health informatics and related standards in China. International Journal of Medical Informatics. 2007; 76(8): 614-20.

5. Jiu W, Yong-yong XU, Dan-hong LIU. Problems and Prospects of Hospital Information System in China. Journal of US-China Medical Science, 2007, 4(1): 76-80.

6. Wang, N. \& Hu, W. Problems and Solution for Domestic HIS's Standardization. China Hospital Manage, 2005, 25(10): 37-39.

7. The problems of HIS development in China, CHINC'2005 Conference, July 3-5, 2005, Beijing.

8. Report of information system for medical treatment organization. Health Insurance Review \& Assessment Service, 2005.12.

9. Chinese Science and Technology Trend Weekly. June $23^{\text {rd }}, 2003$.

10. Twowin Information Systems (200210.14a). Available at: http://www.twowin.co.kr/asp/Masscom/BBSView. 
asp?ID=4\&PageNum=5. Accessed July $9^{\text {th }}, 2006$.

11. Yanbian Korean Autonomous Prefecture government site. Available at: http://www.yanbian.gov.cn/. Accessed September $12^{\text {th }}, 2008$.

12. China Management of hospital classification. Chinese Ministry of Health, 1989.11.29.

13. The People's Republic of China's embassy of Republic of Korea. Available at: http://www.chinaemb.or.kr/ kor/xwxx/t251097.htm. Accessed July $9^{\text {th }}$, 2006.

14. Informatization Promotion Committee. Available at: http://tech.sina.com.cn/it/2006-0302/0705855158.sht $\mathrm{ml}$. Accessed July $9^{\text {th }}, 2006$.

15. Twowin Information Systems (2002.10.14b). Available at: http://www.twowin.co.kr/asp/Masscom/ BBSView. asp?ID=4\&PageNum=5. Accessed July $9^{\text {th }}, 2006$. 